\title{
Congestion Mitigation Scenario through Public Transportation Improvement
}

\author{
Erma Suryani ${ }^{1, *}$, Rully Agus Hendrawan ${ }^{1}$, Phillip Fasrter Eka Adipraja ${ }^{2}$, and Lily Puspa Dewi ${ }^{3}$ \\ ${ }^{1}$ Information Systems, Institut Teknologi Sepuluh Nopember, Kampus ITS, Jalan Raya ITS- Sukolilo-Surabaya, 60111, Indonesia \\ ${ }^{2}$ STMIK Asia Malang, Jl. Soekarno Hatta - Rembuksari 1A Malang, 61234, Indonesia \\ ${ }^{3}$ Informatics Engineering, Petra Christian University, Jalan Siwalankerto 121-131 Surabaya, 60236, Indonesia
}

\begin{abstract}
Congestion can be recognized through roads filled with cars, trucks, buses and sidewalks filled with pedestrians. It usually relates to an excess of vehicles at a particular time resulting in lower speeds, sometimes much slower than normal speeds. Public transportation is a vital element in solving the congestion problem in the city. In Indonesia, currently, safe and convenient transportation modes to move from one point to another still rarely found. Therefore, the growth rate of personal vehicles soaring from year to year. Therefore, in this research a set of simulation models have been developed to mitigate congestion through the improvement of public transportation. As a method used to develop the model, system dynamics is utilized based on consideration that the method can accommodate nonlinear relationships between factors that have significant contribution to mitigate the traffic congestion. Research results show that the improvement of public transportation through comfort, safety, reliability and affordable cost can mitigate the traffic congestion.
\end{abstract}

Keywords: Model, simulation, system dynamics, transportation mode choice.

\section{Introduction}

Transportation has an important role in supporting economic development and social development for the welfare of society [1]. Generally, safe and convenient transportation modes to move from one point to another still rarely found. Therefore, the growth rate of personal vehicles soaring from year to year.

Congestion can be recognized through roads filled with cars, trucks, buses and sidewalks filled with pedestrians. Congestion usually relates to an excess of vehicles on a portion of roadway at a particular time resulting in speeds that are slower-sometimes much slower-than normal or "free flow" speeds [2]. Several sources of congestion are: (i) Traffic-Influencing Events such traffic incident, work zones, and weather; (ii) Traffic Demand that includes special events and fluctuations in normal traffic, (iii) Physical Highway Features such as traffic control devices and road capacity.

Public transport that exists today, some of its forms are less feasible and less secure, the fleet of trains is still minimum so crowded and often there is interference. Based on this condition, a transportation revolution in Indonesia is required. The existence of easy, safe and convenient public transportation is very important not only to congestion mitigation, but also to reduce fuel consumption, as well as to improve the efficiency in mobility. The primary survey has been conducted to collect the data for identifying public preferences for public transport characteristics under four criteria, those are reliability, comfort, safety and cost [3].

Motorcycles in developing countries are a major cause of traffic congestion, accidents, environmental pollution and other social tensions, it is required to plan an appropriate transport system. Although bus service constitutes a small part towards several trips, they are still regarded as an alternative to motorcycle [4]. Previous study has developed a "web based monitoring traffic system". This system is useful in terms of providing surveillance, control and road network

\footnotetext{
*Corresponding author: erma.suryani@gmail.com
} 
monitoring services. The system can integrate complex components in a modular, flexible and open structure to validate models and includes tools to simulate various traffic scenarios and communication technologies [5]. Other study has exploited the emergence of new technologies such as the Internet, to design an intelligent Traffic Management System (TMS) that can monitor traffic and control network traffic located in different locations [6]. The system utilizes a Webbased Embedded Web Server (EWS). Therefore, in this research, a system dynamics simulation model has been utilized to mitigate traffic congestion as a solution to transportation management in urban area.

\section{Literature review}

\subsection{Transportation mode choice}

According to research that have been conducted by Corpuz [7] and Buehler [8], key factors of transportation mode choice are accessibility, waiting time, transportation availability, pleasure, safety, privacy, travel time, distance, price, and fare as seen in Figure 1.

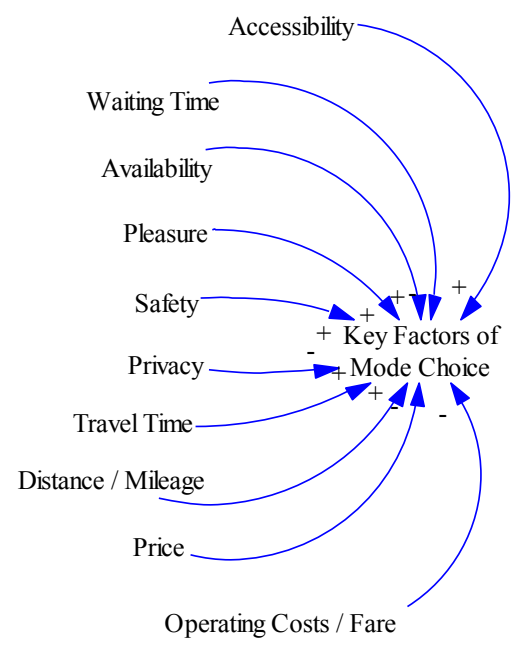

Fig. 1. Key factor of transportation mode choice.

According to Jain et al. [3], there are several factors effecting the choice of public transportation mode, as seen in Table 1. The weights of sub-criteria for global priority and sub criteria can be seen in Table 2. These weights are gathered by conducting questionnaire to people who select public transportation such as metro that is a successful example in terms of offering a comfortable, reliable and safe mode of public transport. Metro is more reliable and comfortable due to its frequency and adherence to schedule, as well as less travel time with air-conditioning facility at most of the metro stations and metro coaches.

Table 1. Factors affecting public transportation system [3].

\begin{tabular}{|c|c|}
\hline $\begin{array}{l}\text { Factors affecting Public } \\
\text { Transportation System }\end{array}$ & Sub-factors \\
\hline \multirow{8}{*}{ Comfort } & Cleanliness \\
\hline & Air conditioning \\
\hline & Seating \\
\hline & Availability \\
\hline & Low floor \\
\hline & Not crowded \\
\hline & Accessibility \\
\hline & Less travel time \\
\hline \multirow[t]{3}{*}{ Safety } & Lesser accident \\
\hline & Personal safety \\
\hline & $\begin{array}{c}\text { Staff behaviour and } \\
\text { attitude }\end{array}$ \\
\hline \multirow[t]{2}{*}{ Reliability } & Good frequency \\
\hline & Adherence to schedule \\
\hline Cost & Cost of travel \\
\hline
\end{tabular}


Table 2. The weights of sub-criteria of public transportation mode choice [3].

\begin{tabular}{|c|c|c|}
\hline Sub-criteria & $\begin{array}{c}\text { Global Priority } \\
\text { Weights }\end{array}$ & $\begin{array}{c}\text { Sub Criteria } \\
\text { Percentage }\end{array}$ \\
\hline Comfort & & \\
\hline Cleanliness & 0.02 & 0.12 \\
\hline Air conditioning & 0.01 & 0.05 \\
\hline Seating availability & 0.02 & 0.12 \\
\hline Low floor & 0.01 & 0.08 \\
\hline Not crowded & 0.03 & 0.16 \\
\hline Accessibility & 0.04 & 0.25 \\
\hline Less travel time & 0.04 & 0.25 \\
\hline Reliability & & \\
\hline Good frequency & 0.16 & 0.61 \\
\hline Adherence to schedule & 0.11 & 0.39 \\
\hline Safety & & \\
\hline Lesser accident & 0.12 & 0.33 \\
\hline Personal safety & 0.15 & 0.42 \\
\hline $\begin{array}{c}\text { Staff behaviour and } \\
\text { attitude }\end{array}$ & 0.09 & 0.25 \\
\hline
\end{tabular}

\subsection{System dynamic simulation}

Dynamic simulation model demonstrates a system as it evolves over time, for example conveyor system in a factory [9]. It is a technique to mimic operations or processes that occur in a system with the help of computer devices so that the system can be learned scientifically. Simulation is an appropriate tool to use, especially if it is required to conduct experiments in order to find the best comments from system components. By conducting a simulation, the study can be conducted in a short time and can provide the right decision, because everything is done with the computer. This system dynamics approach begins with the development of a real system model. The model should be able to show how the various components in the system are interacting so as to truly describe the behaviour of the system. Once the model is created, then the model is transformed into a computer program. System dynamics simulation is a tool for analysing and developing policies. System dynamics is very suitable to be used in handling complex system problem, which is a combination of qualitative and quantitative analysis and based on system thinking and general reasoning. According to Sterman [10], there are five steps in developing a dynamic system model as shown in Figure 2.

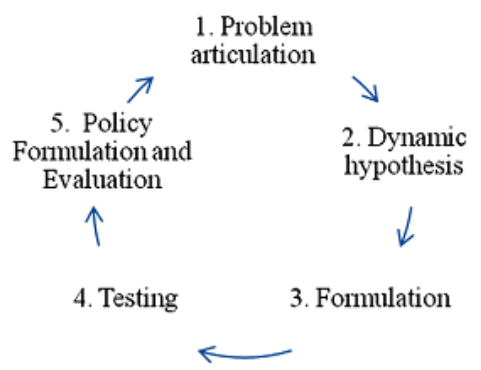

Fig. 2. Steps in developing system dynamics simulation [10].

(i) Problem articulation: In this stage the modeller need to find the problem, determine the significant variables, determine the time period of the simulation, and identify the problem dynamically to provide a basic understanding in designing the policy to solve problems.

(ii) Dynamics hypothesis: In this stage, the development a theory of how the problem arises, creating a causal loop diagram (CLD) that explains the causal relationship between variables, and converts the CLD to the level and rate (Stock and Flow) diagram.

(iii) Formulation: In this stage the modeller needs to define equations that describes the relationship between the variables, estimates the parameters, as well as determine the initial condition.

(iv) Testing: This stage is required to check the model validity, identify the model behaviour, as well as to check whether it can represent the behaviour of real systems.

(v) Policy formulation and evaluation: This stage is the formulation and evaluation of the policy that is proposed. If the structure and model behaviour are in accordance with the actual system, then the model can be utilized to design and evaluate the policy by changing the parameter values or redesigning the new structure to improve the system performance. 


\section{Model development}

This model was developed to perform congestion analysis caused by the internal and external factors. The congestion analysis model consisted of two submodels, those are average daily traffic (ADT) and traffic congestion.

\subsection{Average daily traffic submodel}

Figure 3 shows the average daily traffic volume flow diagram. From Figure 3, it can be seen that the average daily traffic can be grouped into three categories, those are non-passenger, public and private transportation. Public transportation mode choice is one of several factors that influences the volume of private vehicle transportation.

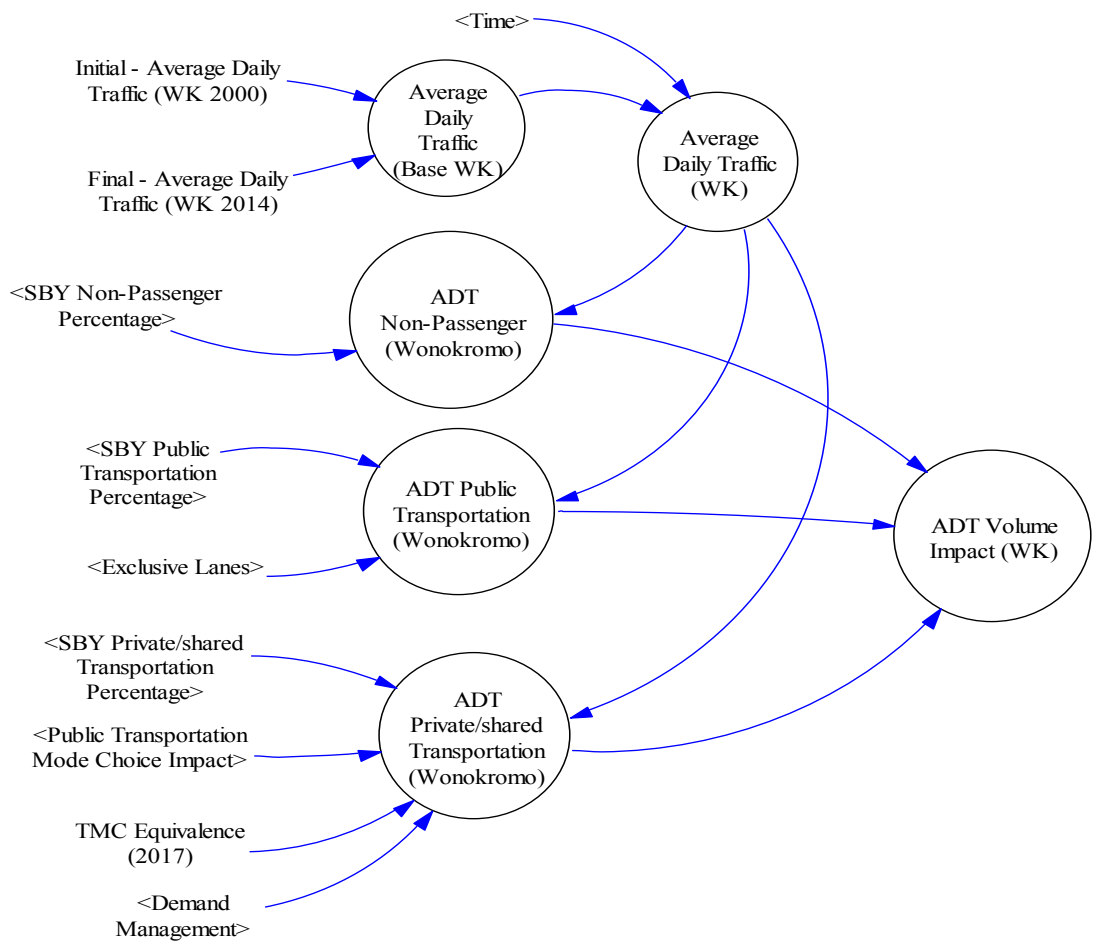

Fig. 3. Flow diagram for Average Daily Traffic (ADT).

From the simulation result, average daily traffic on Wonokromo Road has reached 594985 vehicles per day as seen on Figure 4. Meanwhile, public transportation mode choice has an impact of around $40 \%$ to the number of private transportation, as seen in Figure 5. 


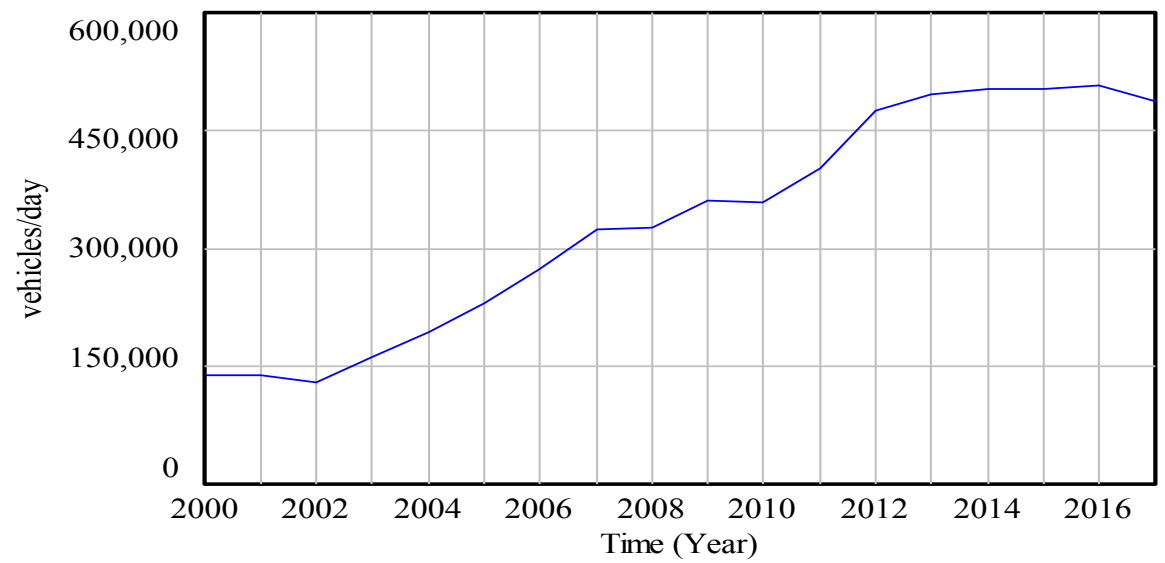

Fig. 4. Average Daily Traffic (ADT) in Wonokromo Street.

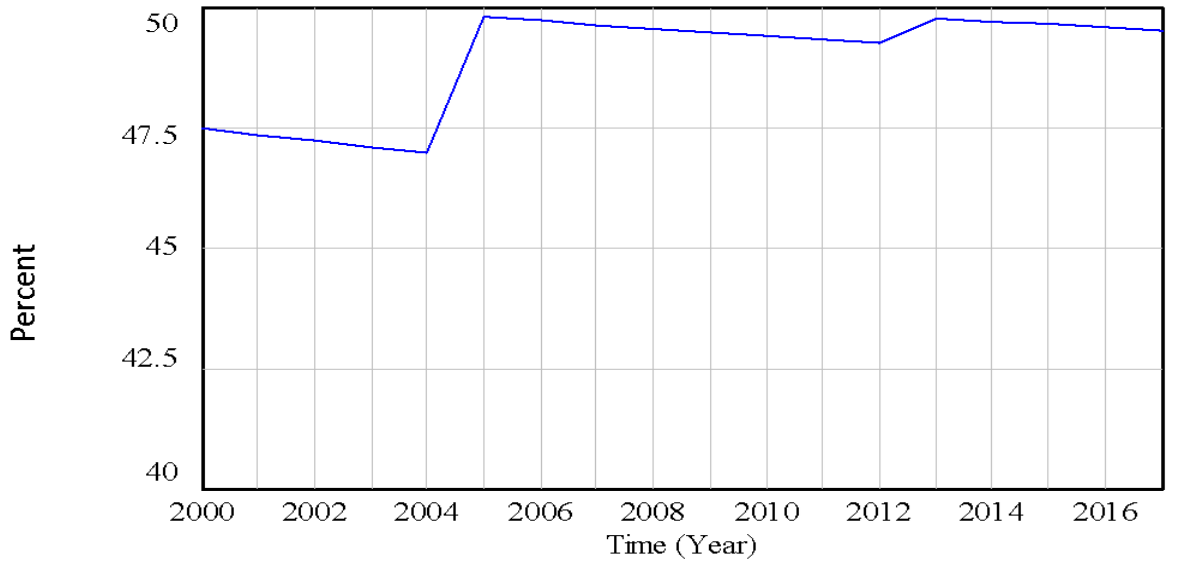

Fig. 5. Public transportation mode choice impact.

\subsection{Traffic congestion submodel}

The flow diagram of the traffic congestion model can be seen in Figure 6. This flow diagram is developed by considering several research results that have been done by Jain [3], Corpuz [7], and Buehler [8]. 


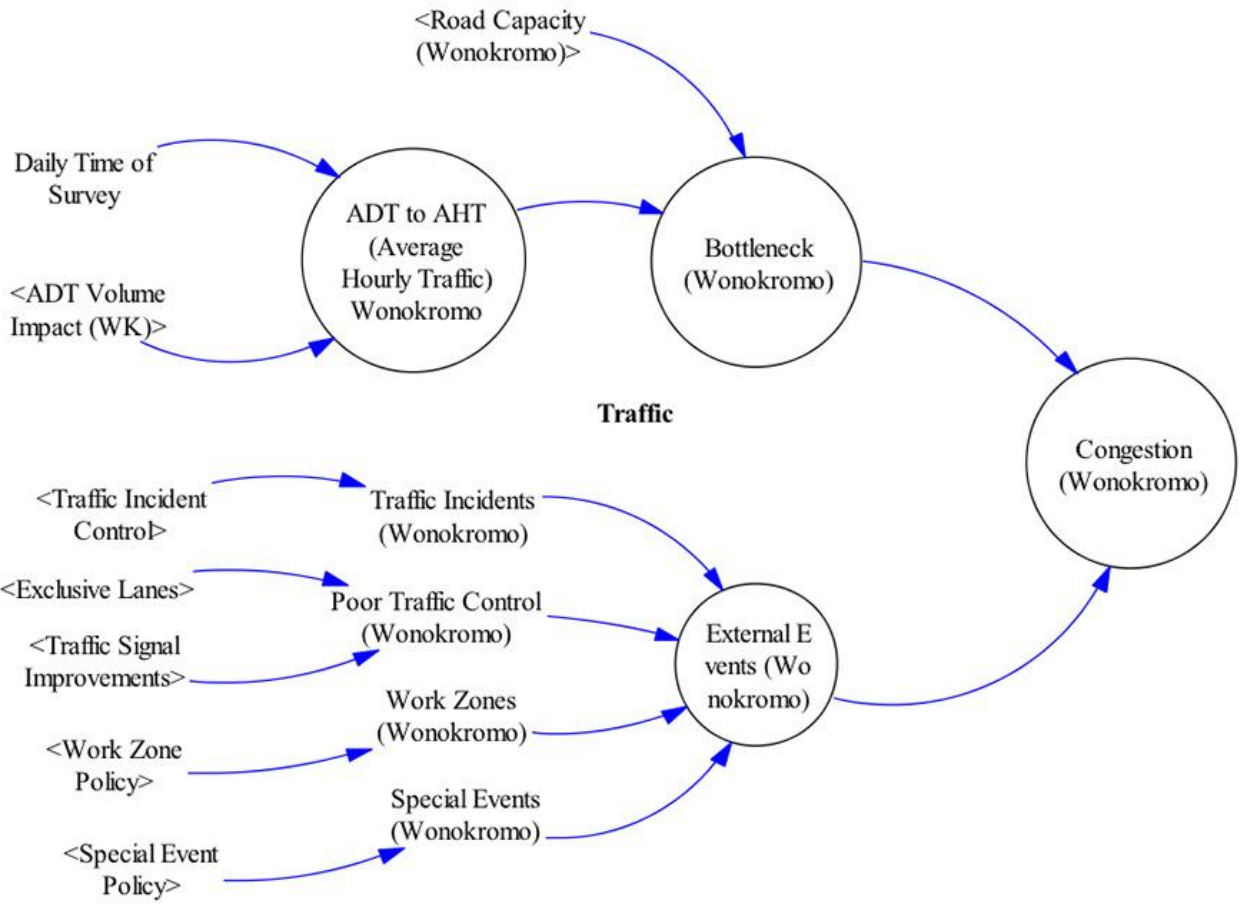

Fig. 6. Traffic congestion flow diagram.

Form Figure 6, it can be seen that traffic congestion depends on the bottleneck (internal factors) and external events (external factors). Some internal factors that affect the bottleneck include road capacity and average daily traffic (ADT). While internal factors are influenced by several factors such as traffic incidents, exclusive lanes, work zones, and special events. Simulation result shows traffic congestion in Wonokromo Road was around $184 \%$ in 2016 as seen in Figure 7.

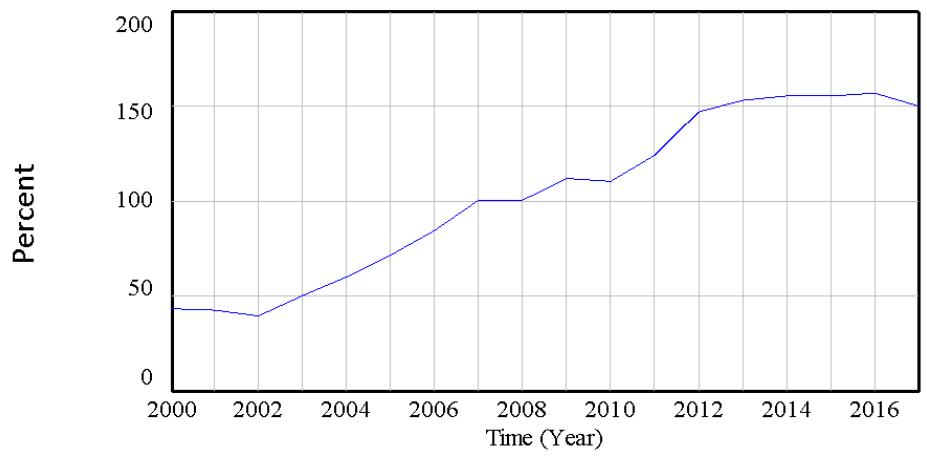

Fig. 7. Simulation result of traffic congestion in Wonokromo Street.

\section{Model validation}

Model validation is required to check the model accuracy. A model will be valid if the error rate is less than $5 \%$ and error variance is less than $30 \%$ [11]. The validation processed has been conducted to check the accuracy of average daily traffic by utilizing the error rate and error variance formulation as defined in Eq. (1) and Eq. (2).

$$
\text { ErrorRate }=\frac{[\bar{S}-\bar{A}]}{\bar{A}}
$$




$$
\text { ErrorVariance }=\frac{|S s-S a|}{S a}
$$

Where:

$\bar{S}=$ The average rate of simulation

$\bar{A}=$ The average rate of data

$S_{\sigma}=$ The standard deviation of simulation

$S_{a}=$ The standard deviation of data

Data use in this research is obtained from city transportation office in Surabaya. Error rate of some variables of daily traffic volume in Wonokromo and A. Yani Street are as follows:

Error rate of "daily traffic volume in Wonokromo Road"

$=\frac{[467763-425968]}{425968}=0.027$

Error rate of "daily traffic volume in A. Yani Road"

$=\frac{[381172-363339]}{363339}=0.04$

Error variance of some variables of daily traffic volume in Wonokromo and A. Yani Street are as follows:

Error variance "daily traffic volume in Wonokromo Road"

$=\frac{[63565-89009]}{89009}=0.28$

Error variance of "daily traffic volume in A Yani Road"

$=\frac{[76045-74095]}{74095}=0.026$

Based on the above calculation, all the error rates are less than $5 \%$, and error of variance are less than $30 \%$ which means that our model is valid.

\section{Scenario development}

This scenario is developed to mitigate traffic congestion through the improvement of public transportation. Several efforts need to be conducted such as increasing comfort, reliability, safety and affordable cost [3] as seen in Figure 8. Those factors will determine the level of user satisfaction in selecting public transport and will have to be raised a shifting from private vehicles to public transport. This is because user would only be willing to shift to transportation modes with greater comfort, reliability and safety.

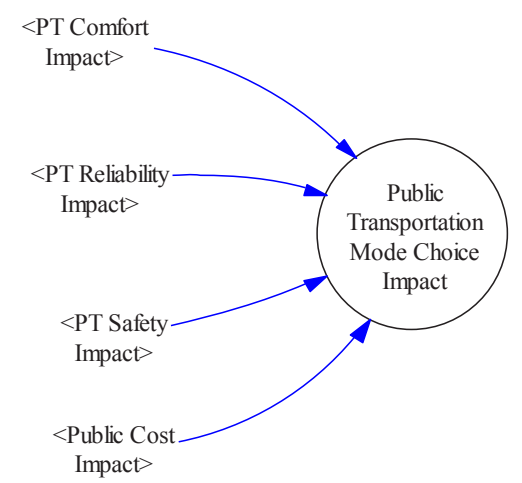

Fig. 8. Scenario of public transportation improvement. 
Public transportation reliability can be done through more frequent of public transport and integrating the scheduling systems [3] as seen in Figure 9.

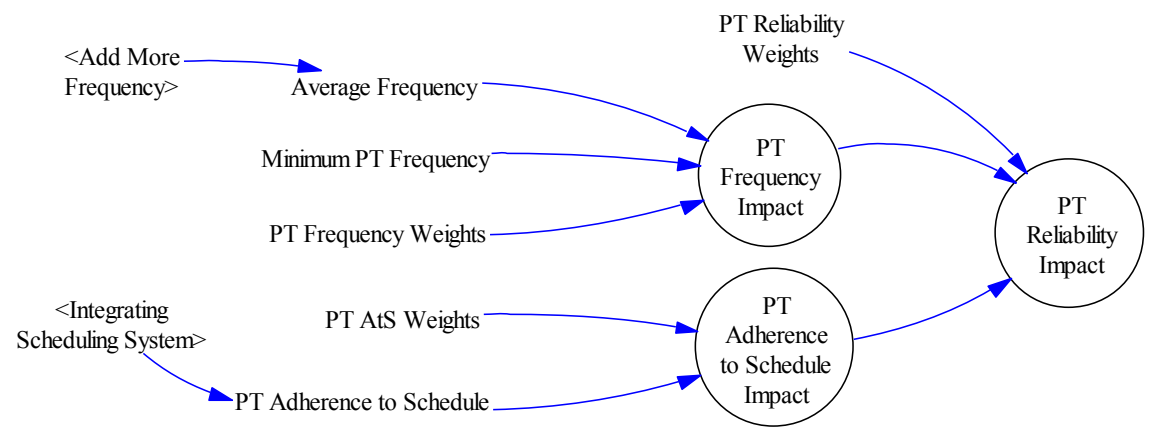

Fig. 9. Reliability improvement.

Safety can be improved through the improvement of cautions, car personal safety, as well as staff behavior and attitude [3] as seen in Figure 10.

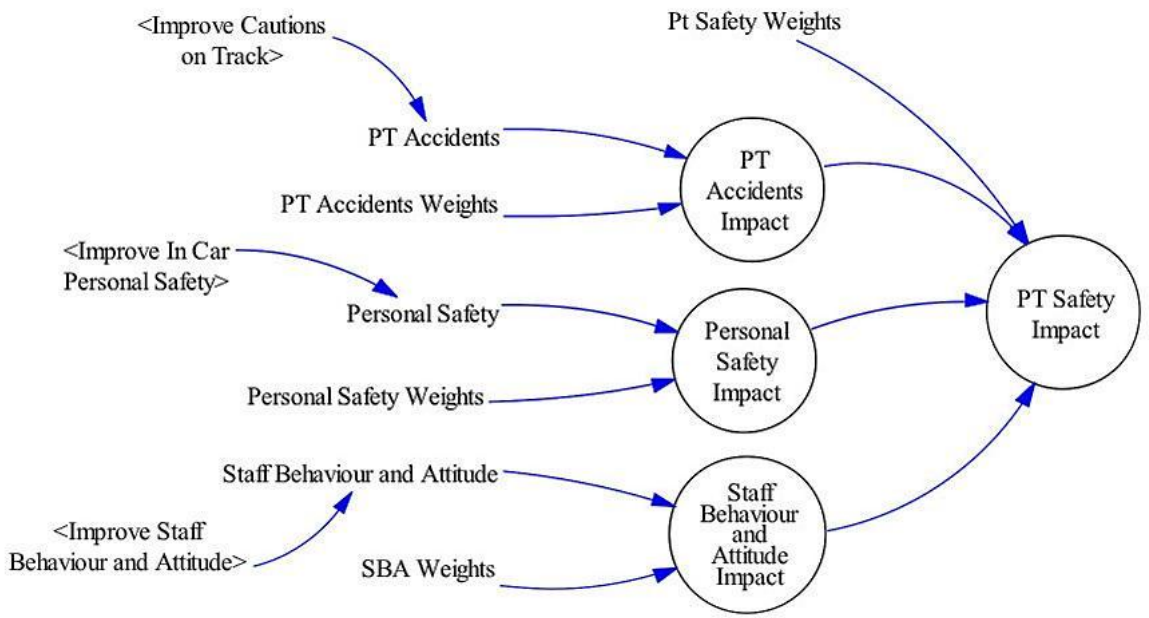

Fig. 10. Safety improvement

Comfort can be improved through the improvement of cleanliness, air conditioning, seat availability, floor level, level of cored accessibility, travel time [3] as seen in Figure 11. 


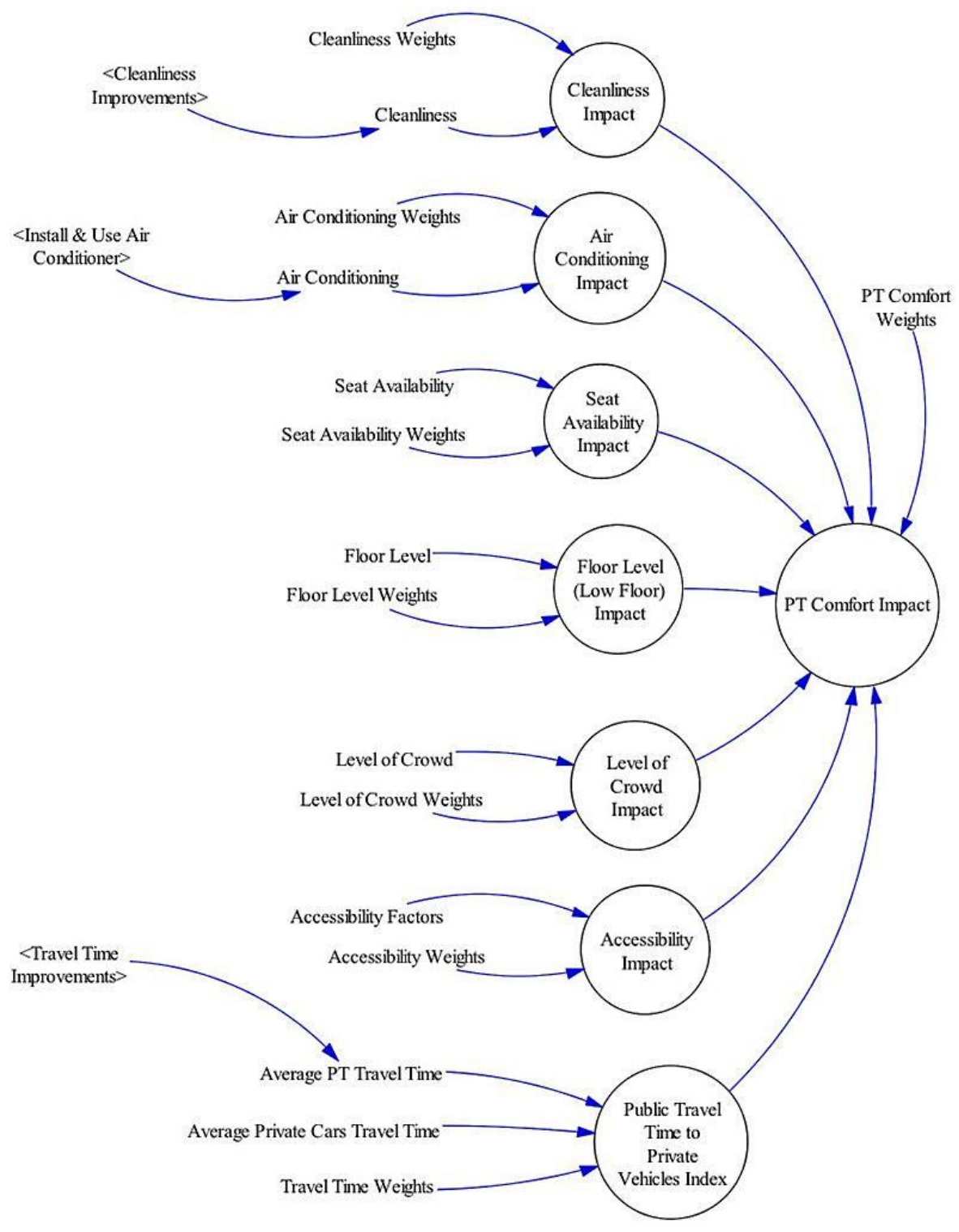

Fig. 11. Comfort improvement

Affordable cost improvement can be done through the increase in parking cost for private transportation, increase Pertamax price, and increase yearly tax of private transportation [12] as seen in Figure 12. Passenger cars and freight cars with an allowable amount of weight of less than or equal to $3500 \mathrm{~kg}$, including: (i) mini truck vehicle or other similar vehicle, imposed retribution of IDR 5 000; (ii) Sedan vehicle, pickup car or other vehicle some kind of levy is IDR 3 000. Passenger cars and freight cars with an allowable amount of weight of more than $3500 \mathrm{~kg}$, including: (i) truck vehicle with trailer, trailer or vehicle other similar type, imposed a levy of IDR 8000 ; (ii) vehicle truck, bus or other large/heavy equipment similar type, charged IDR 7000. 


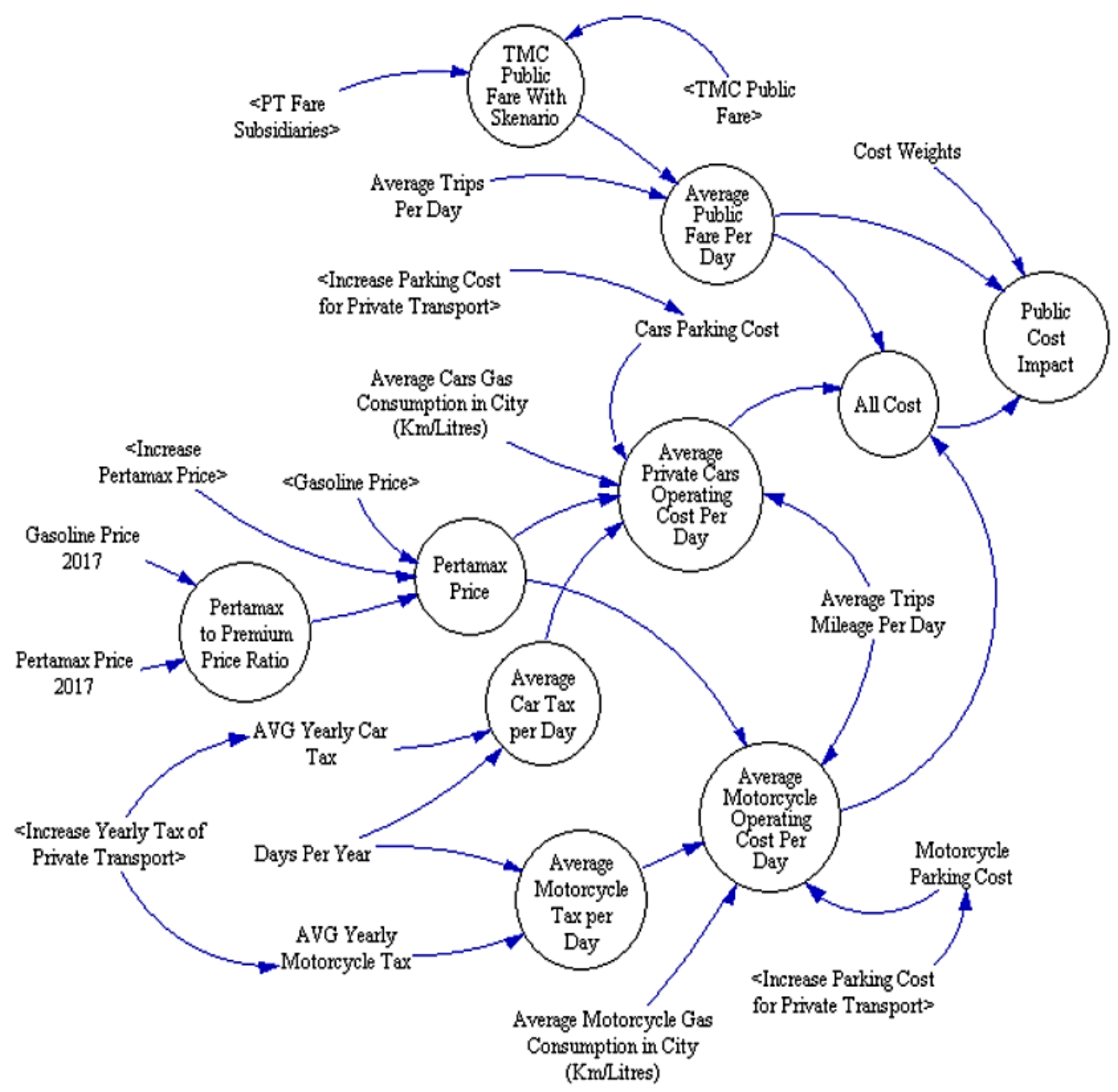

Fig. 12. Cost improvement.

Simulation result of traffic congestion mitigation can be seen in Figure 13. From Figure 13, it can be seen that traffic congestion after the improvement of public transportation such as the improvement of comfort, safety, and reliabilty, as well as the decrease in cost, congestion can be reduced to be around $62 \%$. The congestion mitigation is due to the decrease in traffic volume as many users choose public vehicles and the decrease in the impact of external events that can be done through the control of incident traffic, exclusive lanes, traffic signal improvements, as well as work zones and special event policies. 


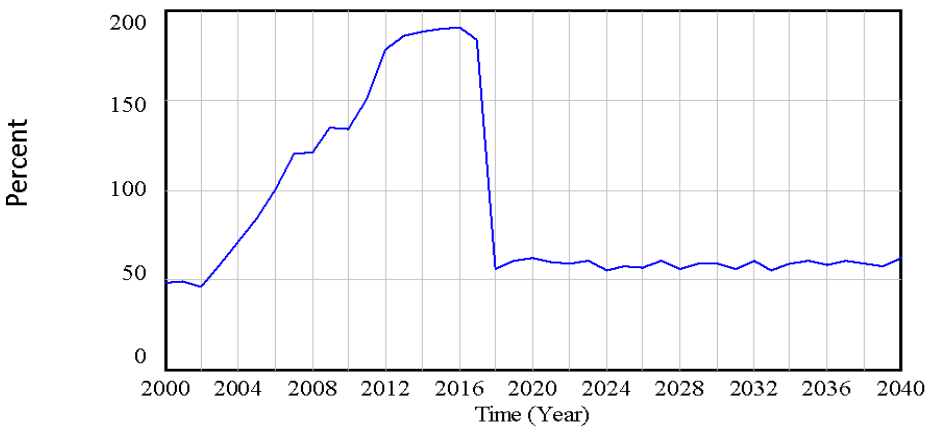

Fig. 13. Congestion mitigation after the improvement of public transportation.

\section{Conclusion}

In developing system dynamics model, system understanding is required as the basic building block for the model development. Traffic congestion depends on the bottleneck (internal factors) and external events (external factors). Some internal factors that affect the bottleneck include road capacity and average daily traffic (ADT). While external factors are influenced by several factors such as traffic incidents, exclusive lanes, work zones and special events. Traffic congestion mitigation can be done through the improvement of public transportation. Several efforts need to be conducted such as increasing comfort, reliability, safety and affordable cost. Traffic congestion mitigation after the improvement of public transportation can be reduced to be around $62 \%$.

This research is a collaboration research supported by ITS Research Center and Ministry of Research, Technology, and Higher Education.

\section{References}

1. Bappenas. Kajian pembangunan transportasi dan perubahan iklim dalam mendukung konektivitas dan pembangunan berkelanjutan. [Study of transportation and climate change in supporting sustainable connectivity and development] Executive Summary. [Online] from https://www.bappenas.go.id/index.php/download_file/.../8581/ (2013). [Accessed on 10 March 2017]. [in Bahasa Indonesia].

2. US Department of Transportation, Traffic congestion and reliability: trends and advanced strategies for congestion mitigation. [Online] from https://ops.fhwa.dot.gov/congestion_report/ (2005). [Accessed on 12 May 2017].

3. S. Jain, P. Aggarwal, P. Kumar, S. Singhal, P. Sharma. Transp Res Part F: Traffic Psychol Behav 24:60-70 (2014). https://www.sciencedirect.com/science/article/pii/S1369847814000382.

4. T.P.L. Lea, T.U. Trinh. Proceedia Engineering 142:236-243 (2016). https://www.sciencedirect.com/science/article/pii/S187770581600401X.

5. C. Avram, A. Astilean, R. Miron. Adv. Eng. Forum, 8-9:3-12 (2013). https://www.scientific.net/AEF.8-9.3.

6. R.A. Alawi. Proceedings of the World Congress on Engineering and Computer Science (San Francisco, USA 2009). WCECS 1:1-4 (2009). http://www.iaeng.org/publication/WCECS2009/WCECS2009 pp504-507.pdf.

7. G. Corpuz. Public transport or private vehicle: factors that impact on mode choice. $30^{\text {th }}$ Australasian Transport Research Forum (Melbourne, 2007). https://scu.rl.talis.com/items/16858C50-C9C3-7E12-65E30026D5CFDF72.html.

8. R. Buehler. J. Trans. Geo. 19(4):644-657 (2011). http://www.sciencedirect.com/science/article/pii/S0966692310001171.

9. A.M. Law. Simulation modeling and analysis 5th edition. New York: McGraw-Hill Education (2014). pp. 5. https://www.amazon.com/Simulation-Mcgraw-hill-Industrial-Engineering-Management/dp/0073401323.

10. J. Sterman, J.D. Sterman. Business dynamics: Systems thinking and modeling for a complex world. Boston: McGraw-Hill (2000). pp. 87. https://www.amazon.com/Business-Dynamics-Systems-ThinkingModeling/dp/007238915X.

11. Y. Barlas. Syst. Dyn. Rev. 12(3):183-210 (1996). http://onlinelibrary.wiley.com/doi/10.1002/(SICI)10991727(199623)12:3\%3C183::AID-SDR103\%3E3.0.CO;2-4/abstract.

12. Department of Surabaya City Transportation. Perubahan tarif retribusi pelayanan parkir di jalan umum, Peraturan Walikota Surabaya no. 36. [Change of parking services tariff at the right of public road, Surabaya 
Mayor's Regulation no. 36]. Surabaya: Department of Surabaya City Transportation (2015). [in Bahasa Indonesia]. http://dishub.surabaya.go.id/backend/upload/files/peraturan/PERDA/perwali 1675.pdf. 